\title{
Psychiatric Symptoms and the Upper Esophageal Sphincter
}

\author{
Pedro Norton Gonçalves Dias ${ }^{1}$, Rafael Melillo Laurino Neto ${ }^{1}$, Fernando A. M. Herbella ${ }^{2}$, \\ Andre Zugman ${ }^{3}$, Francisco Schlottmann ${ }^{4}$, Marco G. Patti ${ }^{4}$
}

'Department of Surgery, Escola Paulista de Medicina, Săo Paulo, Brazil

2Department of Surgery, Escola Paulista de Medicina, Săo Paulo, Brazil

Hospital Săo Luiz Morumbi, Săo Paulo, Brazil

${ }^{3}$ Department of Psychiatric, Escola Paulista de Medicina, Săo Paulo, Brazil

${ }^{4}$ Department of Surgery, University of North Carolina at Chapel Hill, Chapel Hill, USA

\section{ABSTRACT}

Introduction: There is a significant association between psychiatric diseases and esophageal disorders. The upper esophageal sphincter (UES) function may be affected by psychiatric diseases. This study aims to evaluate the correlation between psychiatric symptoms (anxiety and depression) and UES pressure.

Methods: We retrospectively reviewed data from 200 adult patients (median age 41 (34-53) years; $47 \%$ males). All patients underwent high-resolution esophageal manometry and ambulatory $\mathrm{pH}$ monitoring. UES basal pressure (UESP) was measured at the beginning of the test at the point of maximum pressure as an average of a period of 20 seconds after a period of adaptation. Hospital Anxiety and Depression Scale (HADS) was used to evaluate the presence of anxiety and depressive symptoms.

Results: Median UESP was 80 (56-108) $\mathrm{mmHg}$. There were 53 (26\%) hypotonic $(51 \%$ female, median age 43 (34-51) years), $100(50 \%)$ normotonic (53\% female, median age 42 (35-53) years) and 47 (23\%) hypertonic (53\% female, median age 38 (32-52) years) UES. There was no difference in HADS scores among groups. There was no correlation between UESP and HADS scores

Conclusion: UESP does not correlate with minor psychiatric disorders.

Key words: upper esophageal sphincter, esophageal manometry, minor psychiatric disorders

\section{INTRODUCTION}

The association between psychiatric diseases and esophageal disorders is well demonstrated in the literature even though the pathophysiology of this association is still not fully clear $(1,2)$. The study of the interaction between psychopatological symptoms and upper digestive complaints is essential, as both have increased in the Western society.

The upper esophageal sphincter (UES) is composed of skeletal muscle and thus under certain voluntary control (3). Therefore, UES function may be influenced by emotional state and psychiatrics diseases.

This study aims to evaluate the correlation between psychiatric symptoms

\author{
Corresponding author: \\ Dr. Fernando Herbella \\ Rua Diogo de Faria 1087 cj 301 \\ Săo Paulo - SP 04037-003 Brazil \\ Phone/fax: 55-11-39267610 \\ E-mail: herbella.dcir@epm.br
}

Received: 09.02.2020

Accepted: 15.04 .2020

Copyright @ Celsius Publishing House www.sgo-iasgo.com 
(anxiety and depression) assessed by a brief instrument designed to be used in general medical settings and UES pressure.

\section{METHODS}

\section{Population}

We retrospectively analyzed data from 200 adult patients [median age 41 (34-53) years; $47 \%$ males] that underwent esophageal manometry. Data came from a sub-analysis of a previous study (4). Patients with previous gastrointestinal surgery or esophageal dysmotility were excluded from the study.

\section{Esophageal tests}

All patients underwent high-resolution esophageal manometry as previously described (3). In summary, tests were performed after 8 hours of fasting and discontinuation of any medication that could affect esophageal motility. UES basal pressure (UESP) was measured at the beginning of the test at the point of maximum pressure as an average of a period of 20 seconds after a period of adaptation. Normal range (58 - $109 \mathrm{mmHg}$ ) was defined based on previous study in volunteers (5).

All patients also underwent ambulatory $\mathrm{pH}$ monitoring. Patients with a composite score (DeMeester score) > 14.7 were considered as having gastroesophageal reflux disease (GERD) + .

All esophageal function tests were performed and interpreted by the same investigator.

\section{Psychiatric Evaluation}

Hospital Anxiety and Depression Scale (HADS) was used to evaluate psychiatric symptoms (6). This self-assessed form has 14 questions and 2 domains, 7 questions are focused on the assessment of anxiety (HADS-A) and 7 of depression (HADS-D). Each question can be scored from 0 to 3 , composing a maximum score of 21 points for each domain. The HADS have been used to assess dimension of anxiety and depression in different settings, including patients under general medical care and is shown to have good sensitivity for both depressive and anxiety disorders (6).

\section{Statistical analyses}

Shapiro-Wilkins test showed a non-normal distribution for UESP (W=0.95484; $p=0.00001)$. Variables were treated as non-parametric and presented as median (interquartiles 25-75).

Mann-Whitney, Kruskall-Wallis and Pearson correlation tests were used when appropriate. $p<0.05$ was considered significant.

\section{Ethics}

The study protocol was approved by the local Ethics Committee and written informed consent was obtained from each subject. No financial compensation was provided to the individuals. The Authors had no conflict of interest. All authors contributed sufficiently to be named as authors and are responsible for the manuscript. No professional or ghost writer was hired. The current data is a subnalaysis of the same population studied in a different manuscript (4).

\section{RESULTS}

\section{Manometry}

Median UESP was 80 (56-108) $\mathrm{mmHg}$. There were $53(26 \%)$ hypotonic (51\% female, median age 43 (3451) years), 100 (50\%) normotonic ( $53 \%$ female, median age $42(35-53)$ years) and 47 (23\%) hypertonic (53\% female, median age 38 (32-52) years) UES.

\section{Psychiatric Evaluation}

In the hypotonic UES group, the median of HADS score were for HADS-T 13(8-19), HADS-A 7(5-10) and HADS-D 6(3-8). In the normotonic UES group: for HADS-T 13(9-19), HADS-A 8(5-11) and HADS-D 6(3.758). In the hypertonic group: 12(8-18), 8(4.5-11), 4(2-7), for HADS-T, HADS-A and HADS-D, respectively. There was no statistical difference in HADS scores among groups (table 1).

\section{Correlation between UESP and psychiatric evaluation}

There was no correlation between UESP and HADS scores (figure 1).

\section{DISCUSSION}

The manometric study of the UES has been neglected until recent when high-resolution manometry surpassed some technical limitations inherent to conventional manometry (7). Different and complex parameters have been created to understand the motorphysiology of the UES $(5,7,8)$; however, few 
Table 1 - HADS score, age and gender in the hypotonic, normotonic and hypertonic upper esophageal sphincter groups

\begin{tabular}{|c|c|c|c|c|}
\hline & Hypotonic & Normotonic & Hypertonic & p \\
\hline HADS T & $13(8-19)$ & $13(9-19)$ & $12(8-18)$ & $\begin{array}{c}\text { Hypo } \times \text { normo }=0.91 \\
\text { Hypo } \times \text { hyper }=0.44 \\
\text { Normo } \times \text { hyper }=0.32\end{array}$ \\
\hline HADS A & $7(5-10)$ & $8(5-11)$ & $8(4-11)$ & $\begin{aligned} \text { Hypo } \times \text { normo } & =0.95 \\
\text { Hypo } \times \text { hyper } & =0.89 \\
\text { Normo } \times \text { hyper } & =0.89\end{aligned}$ \\
\hline HADS D & $6(3-8)$ & $6(3-8)$ & $4(2-7)$ & $\begin{array}{c}\text { Hypo } \times \text { normo }=0.69 \\
\text { Hypo } x \text { hyper }=0.17 \\
\text { Normo } x \text { hyper }=0.05\end{array}$ \\
\hline $\begin{array}{l}\text { FEMALE } \\
\text { MALE }\end{array}$ & $\begin{array}{l}27 \\
26\end{array}$ & $\begin{array}{l}53 \\
47\end{array}$ & $\begin{array}{l}25 \\
22\end{array}$ & $\begin{array}{c}\text { Hypo } \times \text { normo }=0.9 \\
\text { Hypo } \times \text { hyper }=0.84 \\
\text { Normo } \times \text { hyper }=1\end{array}$ \\
\hline AGE & $43(34-51)$ & $42(35-53)$ & $38(32-52)$ & $\begin{array}{c}\text { Hypo } \times \text { normo }=0.8 \\
\text { Hypo } x \text { hyper }=0.3 \\
\text { Normo } x \text { hyper }=0.2\end{array}$ \\
\hline
\end{tabular}

HADS: hospital anxiety and depression scale. Values reported represent the median (interquartiles 25-75) or the number of participants.

studies considered the fact that the UES is composed of striated muscle and under certain voluntary control. Thus, UES manometric parameters may be affected by head position (9), lingual effort (10), swallowing effort (11) and even varies during the duration of the esophageal manometry test (12). All these variables may account for the ample range of normality found for the UESP $(5,7,13)$. The effect of psychiatric symptoms on the UES; however, have been poorly studied.

Psychiatric disorders unquestionably affect the digestive system. There is an association between psychiatric disorders and functional gastrointestinal syndromes (14). The association with esophageal diseases, especially with UES disorders, are less clear

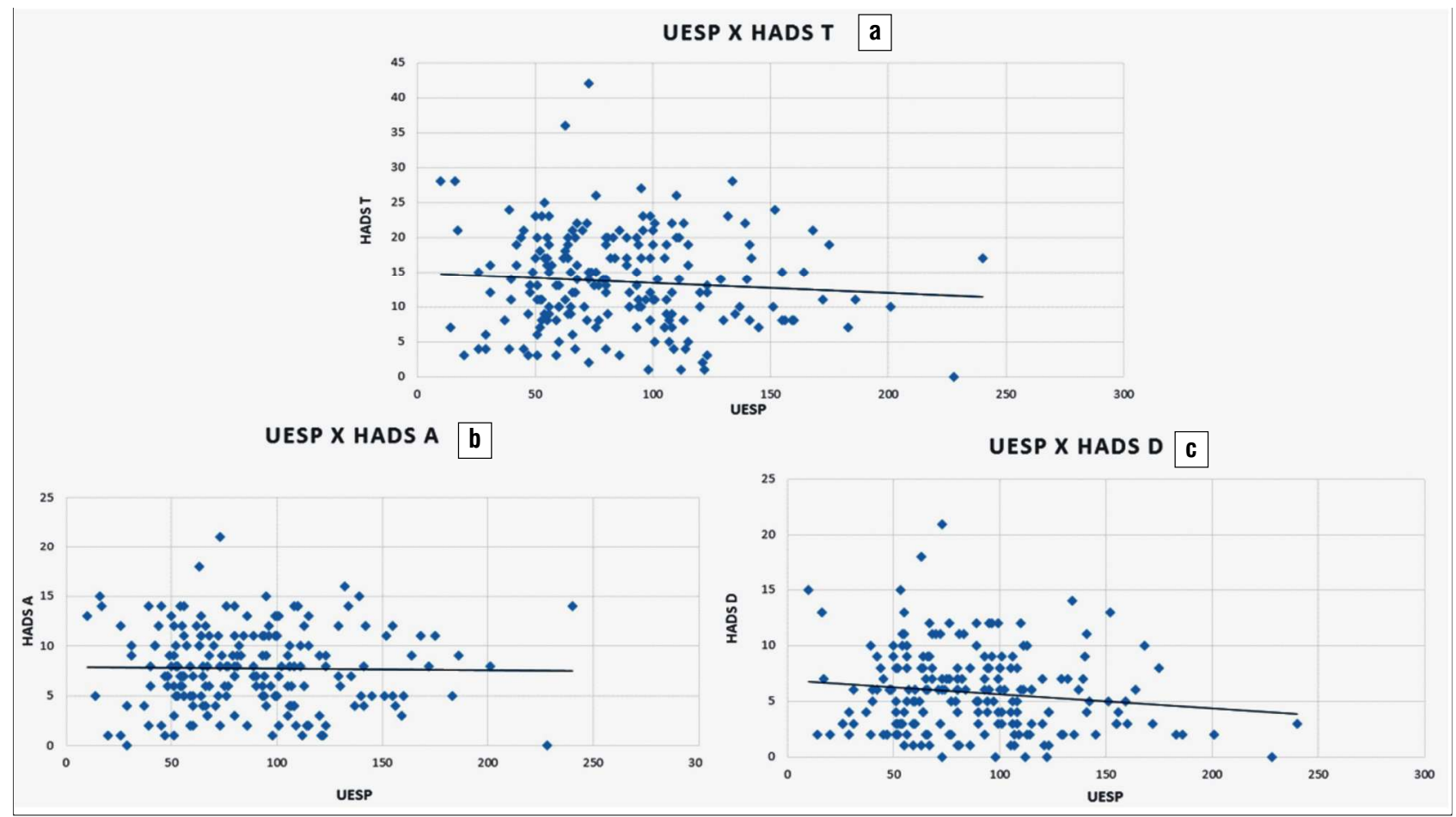

Figure 1 - Relationship between upper esophageal sphincter basal pressure (UESP) and HADS-T score $(p=0.23)(a)$, HADS-A score $(p=0.8)(b)$ and HADS-D score $(p=0.05)(c)$ 
and controversial since the incidence of psychiatric symptoms is elevated in patients with putative UES dysfunction such as in globus patients but manometric patterns in psychiatric patients has not been proven $(15,16)$. We did not find a correlation between UESP and psychiatric symptoms. In fact, most previous studies showed altered visceral sensitivity but not changes in UES motility in patients with psychiatric disorders $(15,17)$.

\section{Study limitations, strengths and comparison to similar studies}

Our study has some limitations: (1) it is a retrospective subanalysis of previous collected data even though a large number of patients was reviewed encompassing a large range of UESP and HADS scores; and (2) we limited the manometric analysis to the UESP. We believe that more detailed manometric parameters are still not fully clinically understood and they probably represent complex neural reflexes less under psychological influence.

There are few studies correlating UES motility and psychiatric disorders and all of them are focused on globus or extra-esophageal symptoms of reflux $(15,17-19)$.

\section{CONCLUSIONS}

This study found no correlation between UESP and anxiety and depressive symptoms. This highlight the fact that somatic complains should be thoughtfully examinated.

\section{Conflict-of-interest statement}

There are no conflicts of interest to report.

\section{Author's contribution}

PNGD: Protocol/project development; Data collection or management; Data analysis; Manuscript writing/editing. RMLN: Protocol/project development; Data collection or management; Data analysis; Manuscript writing/editing. FAMH: Protocol/project development; Data collection or management; Data analysis; Manuscript writing /editing. MGP: Manuscript writing/editing.

\section{Conflicts of Interest and Source of Funding: none}

\section{REFERENCES}

1. Song EM, Jung HK, Jung JM. The association between reflux esophagitis and psychosocial stress. Dig Dis Sci. 2012;58(2):471-7.

2. Lee SP, Sung IK, Kim JH, Lee SY, Park HS, Shim CS. The effect of emotional stress and depression on the prevalence of digestive diseases. J Neurogastroenterol Motil. 2015;21(2):273-82.

3. Rezende DT, Herbella FAM, Silva LC, Panocchia-Neto S, Patti MG. Upper esophageal sphincter resting pressure varies during esophageal manometry. ABCD Arq Bras Cir Dig 2014;27(3):182-183.

4. Neto RML, Herbella FAM, Zugman A, Velanovich V, Montera B, Schlottmann F, Patti MG. Minor psychiatric disorders and objective diagnosis of gastroesophageal reflux disease. Surg Endosc. 2019;33(12):4116-4121.

5. Silva LC, Herbella FA, Neves LR, Vicentine FP, Neto SP, Patti MG. Anatomophysiology of the pharyngo-upper esophageal area in light of high-resolution manometry. J Gastrointest Surg. 2013; 17(12):2033-8.

6. Bjelland I, Dahl AA, Haug TT, Neckelmann D. The validity of the Hospital Anxiety and Depression Scale. An updated literature review. J Psychosom Res. 2002;52(2):69-77.

7. Bhatia SJ, Shah C. How to perform and interpret upper esophageal sphincter manometry. J Neurogastroenterol Motil. 2013;19(1):99-103

8. Cock C, Omari T. Diagnosis of Swallowing Disorders: How We Interpret Pharyngeal Manometry. Curr Gastroenterol Rep. 2017; 19(3):11.

9. Kim CK, Ryu JS, Song SH, Koo JH, Lee KD, Park HS, Oh Y, Min K. Effects of Head Rotation and Head Tilt on Pharyngeal Pressure Events Using High Resolution Manometry. Ann Rehabil Med. 2015; 39(3):425-31.

10. Lenius K, Stierwalt J, LaPointe LL, Bourgeois M, Carnaby G, Crary M. Effects of Lingual Effort on Swallow Pressures Following Radiation Treatment. J Speech Lang Hear Res. 2015;58(3):687-97.

11. Nekl CG1, Lintzenich CR, Leng X, Lever T, Butler SG. Effects of effortful swallow on esophageal function in healthy adults. Neurogastroenterol Motil. 2012;24(3):252-6, e107-8.

12. Rezende DT, Herbella FA, Silva LC, Panocchia-Neto S, Patti MG. Upper esophageal sphincter resting pressure varies during esophageal manometry. Arq Bras Cir Dig. 2014;27(3):182-3.

13. Weijenborg PW, Kessing BF, Smout AJ, Bredenoord AJ. Normal values for solid-state esophageal high-resolution manometry in a European population; an overview of all current metrics. Neurogastroenterol Motil. 2014;26(5):654-9.

14. Olden, K.W., Psychosocial factors in functional gastrointestinal disorders: an evolving phenomenon. Neurogastroenterol Motil. 2008:20 Suppl 1:114-20.

15. Cook IJ, Dent J, Collins SM. Upper esophageal sphincter tone and reactivity to stress in patients with a history of globus sensation. Dig Dis Sci. 1989;34(5):672-6.

16. Richter JE, Bradley LC. Psychophysiological interactions in esophageal diseases. Semin Gastrointest Dis. 1996;7(4):169-84.

17. Rommel N, Van Oudenhove L, Arts J, Caenepeel P, Tack J, Pauwels A. Esophageal Sensorimotor Function and Psychological Factors Each Contribute to Symptom Severity in Globus Patients. Am J Gastroenterol. 2016:111(10):1382-1388.

18. Wong MW, Bair MJ, Chang WC, Hsu CS, Hung JS, Liu TT, et al. Clinical and psychological characteristics in gastroesophageal reflux disease patients overlapping with laryngopharyngeal reflux symptoms. J Gastroenterol Hepatol. 2019;34(10):1720-1726.

19. Ding H, Duan Z, Yang D, Zhang Z, Wang L, Sun X, et al. Highresolution manometry in patients with and without globus pharyngeus and/or symptoms of laryngopharyngeal reflux. BMC Gastroenterol. 2017;17(1):109. 